\title{
The Reaction Rate of Edaravone (3-Methyl-1-phenyl-2-pyrazolin-5-one (MCI-186)) with Hydroxyl Radical
}

\author{
Shinji Abe, ${ }^{a}$ Kazuyoshi Kirima, ${ }^{a}$ Koichiro Tsuchiya, ${ }^{* c}$ Masumi Okamoto, ${ }^{a}$ Toyoshi Hasegawa, ${ }^{a}$ \\ Hitoshi HouchI, ${ }^{b}$ Masanori YoshIzUmI,${ }^{a}$ and Toshiaki TAMAKI ${ }^{a}$ \\ ${ }^{a}$ Department of Pharmacology, The University of Tokushima School of Medicine; ${ }^{b}$ Department of Pharmacy, The \\ University of Tokushima School of Medicine; 3-18-15 Kuramoto, Tokushima 770-8503, Japan: ${ }^{c}$ Department of Clinical \\ Pharmacology, Graduate School of Pharmaceutical Sciences, The University of Tokushima; 1-78 Sho-machi, Tokushima \\ 770-8503, Japan. Received July 10, 2003; accepted December 5, 2003; published online December 12, 2003
}

The pyrazoline derivative edaravone is a potent hydroxyl radical scavenger that has been approved for attenuation of brain damage caused by ischemia-reperfusion. In the present work, we first determined the rate constant, $k_{\mathrm{r}}$, at which edaravone scavenges radicals generated by a Fenton reaction in aqueous solution in the presence of the spin trap agent, 5,5-dimethyl-1-pyrroline- $N$-oxide (DMPO), which competed with edaravone. We detected the edaravone radicals in the process of hydroxyl radical scavenging and found that edaravone reacts with hydroxyl radical around the diffusion limit $\left(k_{\mathrm{r}}=3.0 \times 10^{10} \mathrm{M}^{-1} \mathrm{~s}^{-1}\right)$. The EPR (electron paramagnetic resonance) spectrum of the edaravone radical was observed by oxidation with a horseradish peroxidase-hydrogen peroxide system using the fast-flow method. This radical species is unstable and changed to another radical species with time. In addition, it was found that edaravone consumed molecular oxygen when it was oxidized by horseradish peroxidase (HRP)- $\mathrm{H}_{2} \mathrm{O}_{2}$ system, and that edaravone was capable of providing two electrons to the electrophiles. The possible mechanisms for oxidation of edaravone were investigated from these findings.

Key words MCI-186; edaravone; radical; electron paramagnetic resonance (EPR); brain; rate constant

Reactive oxygen species are involved in many varied pathological conditions such as ischemic-reperfusion injury, ${ }^{1,2)}$ cellular aging, ${ }^{3)}$ and progression of arteriosclerosis. ${ }^{4)}$ Lipid peroxidation caused by reactive oxygen species plays an important role in the development of edema and tissue injury in ischemia-reperfusion damage in the brain. ${ }^{5,6)}$ To attenuate oxidative damage, antioxidants that depend on the following modes of action: i) direct scavenging of free radicals, ii) prevention of formation of free radicals, or iii) prevention of lipid peroxidation, followed by interaction by free radicals and unsaturated fatty acids, have been synthesized and used both in vivo and in vitro.

Recently, a new pyrazolin compound, 3-methyl-1-phenyl2-pyrazolin-5-one (edaravone, Fig. 1) was shown to produce marked attenuation of ischemic and postischemic brain edema induced by the occlusion of the middle cerebral artery of rats. ${ }^{7)}$

Preischemic treatment with edaravone prevented brain edema and changes in the concentrations of sodium and potassium ions induced by hemispheric embolization in the rat brain. ${ }^{8}$ In addition, postischemic treatment of edaravone decreased cortical infarction in focal embolization of rats. ${ }^{9)}$ It was reported that the pharmacological actions of edaravone are due to its antioxidant activity. Edaravone can interact with both peroxyl and hydroxyl radicals $\left({ }^{\circ} \mathrm{OH}\right)$, followed by the formation of a stable oxidation product (OPB: 2-oxo-3-

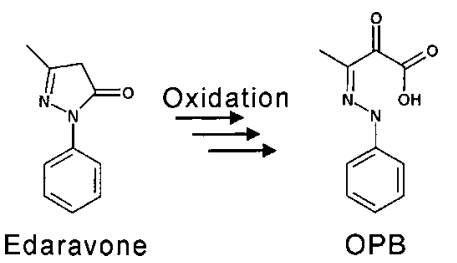

Fig. 1. Chemical Structures of Edaravone and 2-Oxo-3-(phenylhydrazono)-butanoic Acid (OPB)

(phenylhydrazono)-butanoic acid) through a radical intermediate $^{10,11)}$ (Fig. 1).

It was reported that the edaravone inhibited the oxidation of phosphatidylcholine liposomes as efficiently as $1 / 25$ of concentration of vitamin $\mathrm{E}^{10)}$ On the other hand, the rate constant for hydroxyl radical and presence of free radical intermediates of edaravone during the course of oxidation have not yet been reported. Therefore, here we used the fast-flow EPR technique to detect the free radical intermediate of edaravone and the electron paramagnetic resonance (EPR)-spin trapping technique to determine the rate constant for the reaction of edaravone with hydroxyl radicals.

\section{Experimental}

Materials 3-Methyl-1-phenyl-2-pyrazolin-5-one (edaravone) was kindly donated by Mitsubishi Pharma Co. (Osaka, Japan). Horseradish peroxidase (HRP) was purchased from Sigma Chemical Co. (St. Louis, MO, U.S.A.). Hydrogen peroxide $\left(\mathrm{H}_{2} \mathrm{O}_{2}\right)$, and iron(II) sulfate heptahydrate, 2,2-diphenyl1-picrylhydrazyl (DPPH), and cysteine were from Wako Pure Chemical Industries Ltd. (Osaka, Japan). 5,5-Dimethyl-1-pyrroline- $\mathrm{N}$-oxide (DMPO) was purchased from Labotec (Tokyo, Japan). Stock solution of edaravone was prepared before experiments using $0.1 \mathrm{~m}$ phosphate buffer $(\mathrm{pH}$ 7.4). Iron(II) was dissolved with $10 \mathrm{~mm} \mathrm{HCl}$ to make a stock solution before experiments. Other reagents were of the highest quality available from Wako Pure Chemical Industries Ltd.

Methods. Determination of the Rate Constant for the Reaction of Edaravone with $\mathbf{O H}$ The rate constant for the reaction of edaravone with OH was determined by the method of Matuszak with slight modifications. ${ }^{12)}$ Briefly, $5 \mu 1$ DMPO (final conc. $1 \mathrm{mM}$ ), $5 \mu 1$ of $\mathrm{H}_{2} \mathrm{O}_{2}$ (final conc. $0.12 \mathrm{~mm})$, and various concentrations of edaravone $(0-0.3 \mathrm{~mm})$ were dissolved in air-saturated $0.1 \mathrm{M}$ phosphate buffer $(\mathrm{pH} 7.0)$. The reaction was initiated by the addition of $5 \mu$ of iron(II) (final conc. $0.1 \mathrm{~mm}$ ) to the reaction mixture. The final volume of every sample was adjusted to $500 \mu \mathrm{l}$. The sample solution was transferred to a flat quartz EPR cell (Labotec Co., Ltd., Tokyo, Japan), which was, in turn, placed in the cavity of the EPR spectrometer (JES-TE 300, JEOL Co., Ltd., Tokyo, Japan) equipped with a cavity (ES-UCX2, JEOL) at X-band $(9.5 \mathrm{GHz})$. The position of EPR cell in the cavity was fixed for reproducibility. EPR measurements were started $40 \mathrm{~s}$ after the addition of iron(II).

When iron(II) is mixed with $\mathrm{H}_{2} \mathrm{O}_{2}$, $\mathrm{OH}$ occurs by the Fenton reaction (Eq. 1).

* To whom correspondence should be addressed. e-mail: tsuchiya@ph.tokushima-u.ac.jp

C) 2004 Pharmaceutical Society of Japan 


$$
\begin{gathered}
\mathrm{Fe}^{2+}+\mathrm{H}_{2} \mathrm{O}_{2} \rightarrow \mathrm{Fe}^{3+}+\cdot \mathrm{OH}+\mathrm{OH}^{-} \\
R_{\mathrm{f}}=\frac{d\left[{ }^{\cdot} \mathrm{OH}\right]}{d t}=k_{\mathrm{f}}\left[\mathrm{Fe}^{2+}\right]\left[\mathrm{H}_{2} \mathrm{O}_{2}\right]
\end{gathered}
$$

DMPO can trap ${ }^{\circ} \mathrm{OH}$ at a rate of $k_{\mathrm{a}}=4.3 \times 10^{9} \mathrm{M}^{-1} \mathrm{~s}^{-113)}$ (Eq. 2).

$$
\begin{aligned}
& \cdot \mathrm{OH}+\mathrm{DMPO} \stackrel{\mathrm{k}_{\mathrm{a}}}{\longrightarrow} \mathrm{DMPO} / \cdot \mathrm{OH} \\
& R_{\mathrm{a}}=\frac{d[\mathrm{DMPO} / \cdot \mathrm{OH}]}{d t}=k_{\mathrm{a}}[\cdot \mathrm{OH}][\mathrm{DMPO}]
\end{aligned}
$$

If edaravone is oxidized by ${ }^{\circ} \mathrm{OH}$, a radical intermediate can be produced ${ }^{11)}$ (Eq. 5).

$$
\begin{aligned}
& \cdot \mathrm{OH}+\text { edaravone } \stackrel{\mathrm{k}_{\mathrm{r}}}{\longrightarrow} \text { product (edaravone radical) } \\
& R_{\mathrm{r}}=\frac{d[\text { product }]}{d t}=k_{\mathrm{r}}[\cdot \mathrm{OH}][\text { edaravone }]
\end{aligned}
$$

Where $k_{\mathrm{f}}, k_{\mathrm{a}}$, and $k_{\mathrm{r}}$ represent the rate constants for the reaction of $\mathrm{Fe}^{2+}$ with $\mathrm{H}_{2} \mathrm{O}_{2}$, ${ }^{\prime} \mathrm{OH}$ with DMPO, and ${ }^{\prime} \mathrm{OH}$ with edaravone, respectively. In our experimental conditions, the concentration of DMPO should exceed that of ${ }^{\circ} \mathrm{OH}$. Therefore, at steady state approximation for [ $\left.{ }^{\circ} \mathrm{OH}\right], R_{\mathrm{f}}$ can be expressed by the sum of $R_{\mathrm{a}}$ and $R_{\mathrm{r}}$.

$$
R_{\mathrm{f}}=R_{\mathrm{a}}+R_{\mathrm{r}}
$$

where $R_{\mathrm{f}}, R_{\mathrm{a}}$, and $R_{\mathrm{r}}$ indicate the formation rate of ${ }^{\circ} \mathrm{OH}, \mathrm{DMPO} /{ }^{\circ} \mathrm{OH}$, and edaravone radical, respectively.

From Eqs. (2), (4), (6), and (7), the following equation was obtained.

$$
\frac{1}{R_{\mathrm{a}}}=\frac{1}{R_{\mathrm{f}}}+\frac{k_{\mathrm{r}}[\text { edaravone }]}{k_{\mathrm{a}}[\mathrm{DMPO}] R_{\mathrm{f}}}
$$

where $k_{\mathrm{a}}$ and [DMPO] are constant, and a plot of $1 / R_{\mathrm{a}}$ versus [edaravone] gives a straight line with $1 / R_{\mathrm{f}}$ as an intercept and $k_{\mathrm{r}} /\left(k_{\mathrm{a}}[\mathrm{DMPO}] R_{\mathrm{f}}\right)$ as the slope.

In these circumstances, the rate constant for the reaction of ${ }^{\circ} \mathrm{OH}$ with edaravone $\left(k_{\mathrm{r}}\right)$ can be expressed by the following equation.

$$
k_{\mathrm{r}}=\frac{k_{\mathrm{a}}[\mathrm{DMPO}] \text { slope }}{\text { interception }}
$$

Free Radical Analysis Using Fast-Flow EPR We adopted the $\mathrm{HRP}-\mathrm{H}_{2} \mathrm{O}_{2}$ system for one-electron oxidation of edaravone. Due to the short lifespan of edaravone radicals, we used a fast-flow method with slight modification ${ }^{14)}$ to detect them. Two reservoirs were used to supply the solutions to the flat cell. One reservoir held $5 \mathrm{~mm}$ of edaravone and $60 \mu \mathrm{g} / \mathrm{ml}$ of HRP in $0.1 \mathrm{M}$ phosphate buffer ( $\mathrm{pH}$ 7.4), and the other held $2 \mathrm{~mm}$ of $\mathrm{H}_{2} \mathrm{O}_{2}$. Two $50 \mathrm{ml}$ injection syringes (Terumo Co. LTD., Tokyo Japan) were each filled with one of the freshly prepared solutions and connected to the syringe pump (STC-525, Terumo Co., Ltd., Tokyo, Japan) to force these solutions into the flat cell. Polyethylene tubing was used to connect the syringes and the flat cell. At the rates of $135 \mathrm{ml} / \mathrm{h}$ for edaravone and $15 \mathrm{ml} / \mathrm{h}$ for $\mathrm{H}_{2} \mathrm{O}_{2}$, both solutions were introduced into the cell separately, then mixed inside the cell to detect unstable EPR species.

Specific EPR spectrometer settings are given in the figure captions. Hyperfine coupling constants and spectral simulations of EPR spectra were performed using a computer program, Winsim. ${ }^{15)}$

Oxygen-Electrode Studies Changes with oxygen concentration were monitored with a Clark-type oxygen electrode fitted to a $1.8 \mathrm{ml}$ sample cell. The cell was filled with phosphate buffer $(0.1 \mathrm{M}, \mathrm{pH} 7.4)$; then, after $2 \mathrm{~min}$ baseline measurement, $90 \mu \mathrm{l}$ deoxygenated edaravone stock solution $(20 \mathrm{~mm})$ was added. To initiate the one-electron oxidation by the $\mathrm{HRP}-\mathrm{H}_{2} \mathrm{O}_{2}$ system, $18 \mu \mathrm{l} \mathrm{HRP}$ stock solution $(1.2 \mathrm{mg} / \mathrm{ml})$ and $18 \mu \mathrm{H}_{2} \mathrm{O}_{2}$ stock solution $(120 \mathrm{mM})$ were introduced into the chamber $3 \mathrm{~min}$ and $6 \mathrm{~min}$ after edaravone.

DPPH Study The antioxidant efficiency of edaravone was assayed using the DPPH radical dismutation technique with slight modification. ${ }^{16)}$ Briefly, $100 \mu \mathrm{l}$ of DPPH ethanol solution $(0.4 \mathrm{~mm})$ was diluted with $200 \mu \mathrm{l}$ of ethanol, then mixed with $200 \mu \mathrm{l}$ of buffer solution containing $0-250 \mu \mathrm{M}$ of cysteine and edaravone $(0.1 \mathrm{M}, \mathrm{pH} 5.5$ acetate buffer for cysteine, and $0.1 \mathrm{M}$, pH 7.4 phosphate buffer for edaravone, respectively). After $30 \mathrm{~min}$ of incubation, the reaction mixture was transferred to the EPR quartz flat cell, then the EPR spectrum of DPPH radical was measured. The relative concentration of DPPH radical was obtained by double integration of each spectrum using Winsim ${ }^{15)}$ and our own making software. EPR spectrometer settings are given in the figure caption.

\section{Results}

Rate Constant for the Reaction of Edaravone with $\cdot \mathrm{OH}$ Figure $2 \mathrm{~A}$ shows the EPR spectrum of DMPO/ ${ }^{\circ} \mathrm{OH}$ adduct $\left(a^{\mathrm{N}}=14.9\right.$ Gauss, $\left.a^{\mathrm{H}}=14.9 \mathrm{Gauss}\right)$, which was produced by the reaction of $1 \mathrm{~mm}$ of DMPO with $/{ }^{\circ} \mathrm{OH}$ generated by the Fenton reaction. When edaravone was added to the reaction mixture, the EPR signal intensity decreased in proportion to the rise in the edaravone concentration (Figs. 2B-F). The EPR signal of $\mathrm{DMPO} /{ }^{\circ} \mathrm{OH}$ adduct was unchanged by the addition of $0.3 \mathrm{~mm}$ edaravone (Fig. 2G), suggesting that $\mathrm{DMPO} /{ }^{\circ} \mathrm{OH}$ adduct did not react with edaravone. Figure 3 shows the relationship between the reciprocal of the intensity of $\mathrm{DMPO} /{ }^{\circ} \mathrm{OH}$ adduct and sample concentrations. Here, a linear relationship is shown that is in agreement with Eq. 8. The rate constants obtained from Eq. 9 were found to be $3.0 \times 10^{10} \mathrm{M}^{-1} \mathrm{~s}^{-1}$ for edaravone and $1.6 \times 10^{10} \mathrm{M}^{-1} \mathrm{~s}^{-1}$ for salicylic acid, respectively (Table 1), and the rate constant for salicylic acid is in agreement with the value determined previously. ${ }^{17)}$ No DMPO/ $\mathrm{OH}$ adduct was observed $1 \mathrm{~min}$ after incubation of $0.1 \mathrm{~mm}$ iron(III) with $1 \mathrm{~mm}$ edaravone in a $0.1 \mathrm{M}$ phosphate buffer containing $100 \mathrm{~mm}$ DMPO (data not shown), suggesting that edaravone did not reduce iron(III) to iron(II), which is responsible for overestimation of ${ }^{\circ} \mathrm{OH}$ production. In addition, no spectrophotometric change was observed when $50 \mu \mathrm{M}$ edaravone was mixed with either $10 \mu \mathrm{M}$ iron(II) or $12 \mu \mathrm{M} \mathrm{H}_{2} \mathrm{O}_{2}$ in phosphate buffer ( $\mathrm{pH} 7.4,0.1 \mathrm{M}$ ) (data not shown).

Edaravone Radicals Produced by the HRP- $\mathrm{H}_{2} \mathrm{O}_{2}$ System We tried to detect the edaravone radical followed by the one-electron oxidation. When edaravone was mixed with the HRP $-\mathrm{H}_{2} \mathrm{O}_{2}$ system using the fast-flow method, as shown in Figs. 4A and 5, a four-line edaravone radical $(g=2.00)$ with a estimated coupling constant of $a^{\mathrm{N} 1}=7.0$ Gauss, $a^{\mathrm{N} 2}=0.9$ Gauss, and $a^{\mathrm{H}}=6.7$ Gauss was directly observed. The edaravone radical was dependent on the presence of HRP (Fig. 4B) and $\mathrm{H}_{2} \mathrm{O}_{2}$ (Fig. 4C).

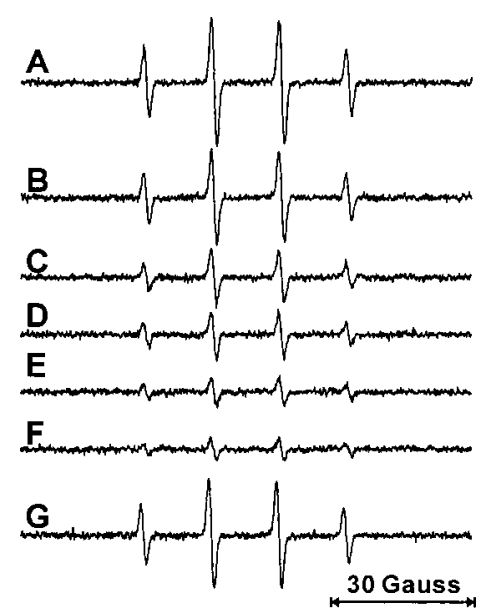

Fig. 2. EPR Spectra of $\mathrm{DMPO} /{ }^{\circ} \mathrm{OH}$ Adduct Obtained at Various Concentrations of Edaravone

A, $0.1 \mathrm{mM} \mathrm{Fe}^{2+}$ and $0.12 \mathrm{mM} \mathrm{H}_{2} \mathrm{O}_{2}$ were introduced into $1 \mathrm{~mm}$ DMPO solution in $0.1 \mathrm{M}$ phosphate buffer ( $\mathrm{pH}$ 7.4). B, C, D, E, and F were introduced as in A, but edaravone $(0.1,0.2,0.3,0.4$ and $0.5 \mathrm{~mm}$, respectively) was pre-mixed in the buffer. $\mathrm{G}, 20 \mathrm{~s}$ after the addition of $\mathrm{Fe}^{2+}$ in solution $\mathrm{A}, 0.5 \mathrm{~mm}$ edaravone was introduced. EPR spectrometer instrumental settings were microwave, $8 \mathrm{~mW}$; modulation amplitude, $1.0 \mathrm{G}$; modulation frequency, $100 \mathrm{kHz}$; sweep time, $2 \mathrm{~min}$; receiver gain, 790. 


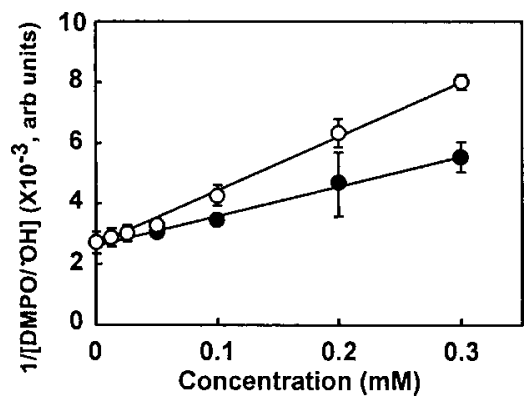

Fig. 3. Reciprocal Plot of DMPO/ OH Adduct Intensities versus the Sample Concentration

Each signal intensity was obtained by double integration of $\mathrm{DMPO} /{ }^{\circ} \mathrm{OH}$ adduct using Winsim ${ }^{15}$ ) and our own making software. Open circle $(\bigcirc)$ represents the competition between DMPO and edaravone, and closed circle $(\bullet)$ between DMPO and salicylic acid for ${ }^{\circ} \mathrm{OH}$ radical. EPR spectrometer instrumental settings were as in Fig. 2.

Table 1. Rate Constants for the Reaction of Hydroxyl Radical with Edaravone and Known Hydroxyl Radical Scavengers

\begin{tabular}{lcc}
\hline \hline Compound & Rate constant $\left(\mathrm{M}^{-1} \mathrm{~s}^{-1}\right)$ & Reference \\
\hline Edaravone & $3.0 \times 10^{10}$ & This work \\
Salicylic acid & $1.6 \times 10^{10}$ & This work \\
& $2.0 \times 10^{10}$ & $17)$ \\
Antipyrine & $1.1 \times 10^{10}$ & $46)$ \\
Formic acid & $3.3 \times 10^{9}$ & $17)$ \\
DMPO & $4.3 \times 10^{9}$ & $13)$ \\
\hline
\end{tabular}
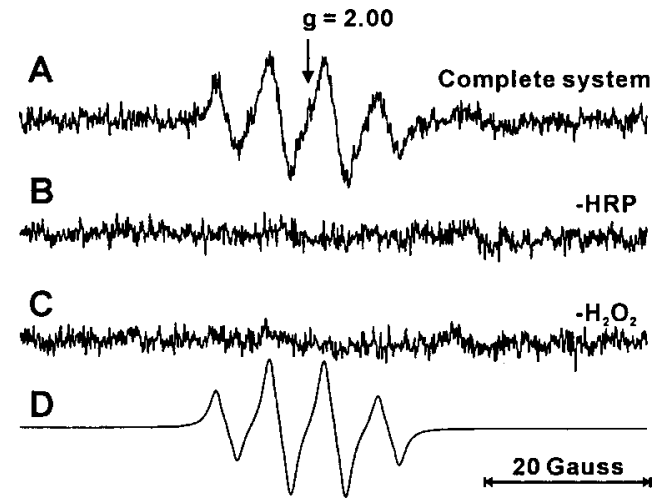

Fig. 4. EPR Spectra of Edaravone Radical Observed by the Fast-Flow Method

A, $5 \mathrm{~mm}$ edaravone and $60 \mu \mathrm{g} / \mathrm{ml} \mathrm{HRP}$ in $0.1 \mathrm{M}$ phosphate buffer ( $\mathrm{pH} 7.4)$ were transferred to a plastic syringe, and another syringe held $6 \mathrm{mM} \mathrm{H}_{2} \mathrm{O}_{2}$. Each of the freshly prepared solutions was injected into the flat cell at a flow rate of $135 \mathrm{ml} / \mathrm{h}$ and $15 \mathrm{ml} / \mathrm{h}$, respectively. B, as in A, but HRP was absent. C, as in A, but $\mathrm{H}_{2} \mathrm{O}_{2}$ was absent. D, computer simulation of spectrum A using the following hyperfine coupling constants $\left(a^{\mathrm{N} 1}=7.0\right.$ Gauss, $a^{\mathrm{N} 2}=0.9$ Gauss, and $a^{\mathrm{H}}=6.7$ Gauss $)$. EPR spectrometer settings were microwave, $8 \mathrm{~mW}$; modulation amplitude, $2.0 \mathrm{G}$; modulation frequency, $100 \mathrm{kHz}$; sweep time, $4 \mathrm{~min}$; receiver gain, 400.

When the initial edaravone concentration was $1 \mathrm{~mm}$, another edaravone radical $(g=2.00)$ with a estimated coupling constant of $a^{\mathrm{N} 1}=7.0$ Gauss and $a^{\mathrm{N} 2}=0.7$ Gauss appeared, followed by a resting state of about $9 \mathrm{~min}$, and maintained its signal intensity until the end of the measurements $(60 \mathrm{~min})$ (Fig. 5).

We present the computer simulation of spectrum $4 \mathrm{~A}$ and the three-line EPR spectrum at 60 min in Fig. 5 using each hyperfine coupling constant mentioned above (Fig. 4D and the bottom spectrum of Fig. 5, respectively).

Oxygen Consumption by Edaravone Radical In 1996,

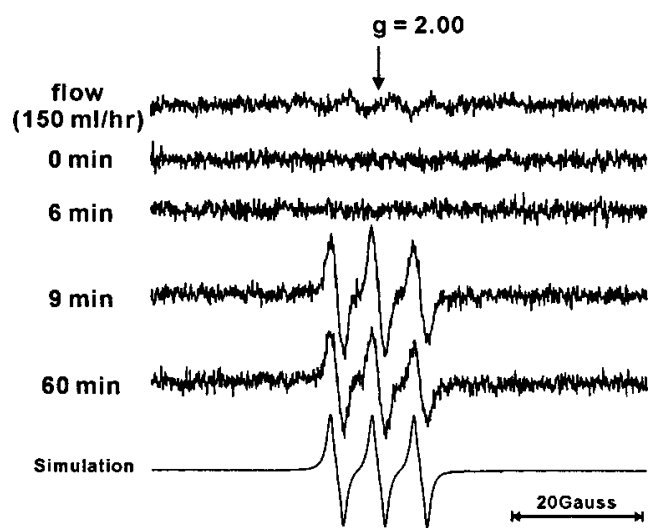

Fig. 5. Changes in the EPR Signals of Edaravone Radicals

$1 \mathrm{~mm}$ edaravone and $12 \mu \mathrm{g} / \mathrm{ml} \mathrm{HRP}$ in $0.1 \mathrm{~m}$ phosphate buffer ( $\mathrm{pH} 7.4$ ) were transferred to one plastic syringe, and another syringe held $1.2 \mathrm{mM} \mathrm{H}_{2} \mathrm{O}_{2}$. Each of the freshly prepared solutions was injected into the flat cell with a flow rate of $135 \mathrm{ml} / \mathrm{h}$ and $15 \mathrm{ml} / \mathrm{h}$, respectively. EPR spectra were measured under the flow condition (Fig. 5, top), and other spectra were obtained after the flow was stopped and solutions incubated for the indicated period. The simulated EPR spectrum of edaravone radical at $t=60 \mathrm{~min}$ was obtained using the following hyperfine coupling constants $\left(a^{\mathrm{N} 1}=7.0\right.$ Gauss, and $a^{\mathrm{N} 2}=0.9$ Gauss $)$. EPR spectrometer settings were as in Fig. 4.

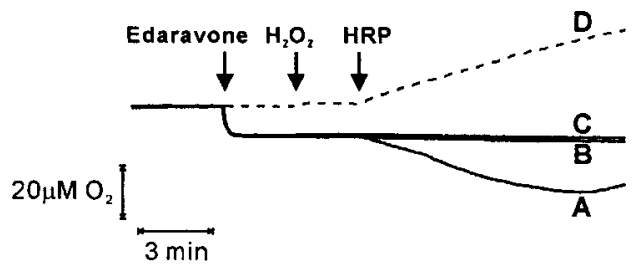

Fig. 6. Oxygen Consumption by the $\mathrm{HRP}-\mathrm{H}_{2} \mathrm{O}_{2}$ System with Edaravone

The system contained $12 \mu \mathrm{g} / \mathrm{ml} \mathrm{HRP}, 1.2 \mathrm{mM} \mathrm{H}_{2} \mathrm{O}_{2}$ and $1 \mathrm{~mm}$ edaravone. A, complete system. B, as in A, but without HRP. C, as in A, but without $\mathrm{H}_{2} \mathrm{O}_{2}$. D, as in A, but without edaravone. The stock solution of edaravone was deoxygenated by passing through $\mathrm{Ar}$ gas for $15 \mathrm{~min}$. The left arrow indicates the point of edaravone introduction, the middle is $\mathrm{H}_{2} \mathrm{O}_{2}$, and the right is HRP. Measurements were performed at room temperature $\left(25^{\circ} \mathrm{C}\right)$.

Yamamoto et al. hypothesized the mechanisms for the production of edaravone radical by a one-electron transfer from edaravone. They expected that edaravone radical interacts with molecular oxygen, yielding edaravone peroxyl radical. This species, in turn, converts to 3-methyl-1-phenyl-2-pyrazolin-4,5-dione (4,5-dione), followed by hydrolysis to give 2-oxo-3-(phenylhydrazono)-butanoic acid (OPB) as an endproduct. ${ }^{10)}$

In contrast, Lehmann et al. reported that the edaravone radical itself does not react with molecular oxygen. ${ }^{18)}$ Therefore, to clarify whether the molecular oxygen participates in the oxidative pathway of edaravone, we measured the oxygen consumption followed by the one-electron oxidation of edaravone by the $\mathrm{HRP}-\mathrm{H}_{2} \mathrm{O}_{2}$ system. As shown in Fig. 6, apparent oxygen consumption was observed when edaravone was added to the HRP- $\mathrm{H}_{2} \mathrm{O}_{2}$ system (Fig. 6A). The oxygen consumption was dependent on the presence of HRP (Fig. 6B) and $\mathrm{H}_{2} \mathrm{O}_{2}$ (Fig. 6C).

DPPH Radical Scavenging Activity by Edaravone DPPH has been used to verify the antioxidative activity of various sorts of antioxidants on the basis of following equation; ${ }^{19)}$

$\mathrm{DPPH}^{\cdot}+\mathrm{HX} \rightarrow \mathrm{DPPHH}^{\circ} \mathrm{X} \quad$ (where $\mathrm{HX}$ represents antioxidant)

Watanabe et al. reported that edaravone was oxidized to 
A
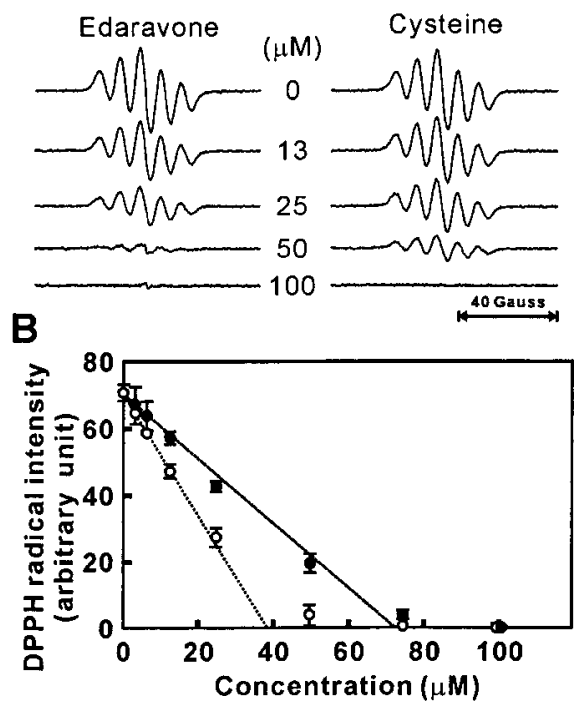

Fig. 7. Effect of Edaravone and Cysteine on DPPH Radical

The reaction mixture consisting of $80 \mu \mathrm{M} \mathrm{DPPH}, 0-100 \mu \mathrm{m}$ edaravone (A, left) and cysteine (A, right) was incubated for $30 \mathrm{~min}$ at room temperature, then the EPR spectrum was measured. Edaravone and cysteine were dissolved with $0.1 \mathrm{M}$ phosphate of $\mathrm{pH}$ 7.4 and $0.1 \mathrm{M}$ acetate buffer of $\mathrm{pH} 5.5$, respectively. The relative DPPH radical concentration was obtained by double integration of each EPR spectrum, then it was plotted against edaravone (B, open circle) and cysteine (B, closed circle) concentrations. EPR spectrometer settings were the same as Fig. 4 but microwave, $20 \mathrm{~mW}$; modulation amplitude, $1.0 \mathrm{G}$; sweep time, $1 \mathrm{~min}$; receiver gain, 250

OPB when it was incubated with DPPH, a stable free radical. ${ }^{20)}$ However, the ratio between DPPH and edaravone was not mentioned. Therefore we used DPPH to titrate the oxidizable groups of edaravone. ${ }^{21)}$ When edaravone was added to the reaction mixture containing $80 \mathrm{~mm}$ DPPH followed by incubation of $30 \mathrm{~min}$, the EPR signal intensity decreased in proportion to the rise in the edaravone concentration, and its activity was more efficient than the same concentration of cysteine (Fig. 7A). To quantify the reactivity of edaravone to DPPH radical, we calculated the DPPH radical concentration by double integration of each EPR spectrum, then plotted the DPPH radical concentration versus sample concentrations (Fig. 7B). It was reported that cysteine quantitatively scavenges the DPPH radical (DPPH + cysteine$\mathrm{SH} \rightarrow \mathrm{DPPHH}+$ cysteine-S$\left.{ }^{*}\right),{ }^{16,21)}$ and this was in good agreement with our result (Fig. 7B). On the other hand, from the interception value of edaravone at the DPPH radical concentration of zero, it appeared that one molecule of edaravone scavenged two DPPH radicals.

\section{Discussion}

With the increase in the average life expectancy, the incidence of cardiovascular diseases such as stroke, myocardial infarction, and hypertension continues to grow. In the clinical management of stroke, a variety of drugs are prescribed depending on their pharmacological properties. For example, tissue plasminogen activator (tPA), ${ }^{22)} \mathrm{N}$-methyl-D-aspartate (NMDA) antagonists, ${ }^{23-25)}$ sodium channel antagonist, ${ }^{26}$ ) calcium channel antagonist, ${ }^{27)}$ chlormethiazole, ${ }^{28)}$ glutamaterelease inhibitor, ${ }^{29)}$ an interferer with nitric oxide's effects, ${ }^{30}$ ) an alleviator of free fatty acid, ${ }^{31)}$ and a free radical scavenger ${ }^{32,33)}$ have been used.

Edaravone is a newly developed free radical scavenger that has been approved in Japan as a neuroprotective drug for at- tenuation of brain ischemic damage in stroke since 2001. In animal experiments ${ }^{8,9,34,35)}$ and in in vitro studies, ${ }^{10)}$ it appeared that edaravone had potent free radical scavenging effects in experimental ischemia.

It was reported that edaravone reduced hydroxyl radical level on cerebral ischemia following rat middle cerebral artery occlusion using salicylate system ${ }^{36}$ ) and edaravone interacts other lipid-derived radical species ${ }^{10)}$ though, few detailed studies have been reported. Therefore, in this study, we further examined the reaction mechanisms for one-electron oxidation of edaravone.

First, we determined the rate constant of edaravone for hydroxyl radical at neutral $\mathrm{pH}$. The rate constant of edaravone for hydroxyl radical $\left(3.0 \times 10^{10} \mathrm{M}^{-1} \mathrm{~s}^{-1}\right)$ was double that of salicylate $\left(1.6 \times 10^{10} \mathrm{M}^{-1} \mathrm{~s}^{-1}\right)$, a potent hydroxyl radical scavenger. ${ }^{17,37)}$ The combination of salicylate hydroxylation and the microdialysis technique is widely recognized as an evaluation method for hydroxyl radical formation in living systems. ${ }^{38,39)}$ It was reported that edaravone administration to the experimental animals significantly reduced the formation of dihydroxybenzoic acid in middle cerebral artery (MCA) occlusion $^{36)}$ and transient cerebral ischemia in rats. ${ }^{40)}$ These results are supported by our present finding that edaravone acts as a hydroxyl radical scavenger similar to salicylate.

Next, we studied the radical scavenging mechanisms of edaravone. In 1989, Lehmann et al. first reported the EPR signal of edaravone by both $\mathrm{HRP}-\mathrm{H}_{2} \mathrm{O}_{2}$ and potassium hexacyanoferrate-mediated oxygenation systems with a $1: 1: 1$ three-line signal and a coupling constant of $a^{\mathrm{N}}=6.7$ Gauss. ${ }^{18}$ ) Interestingly, this EPR signal was augmented with a lag time (ca. $2 \mathrm{~min}$ ), and it was dependent on the $\mathrm{H}_{2} \mathrm{O}_{2}$ concentration. In general, it has been accepted that the oxidation rate by the $\mathrm{HRP}-\mathrm{H}_{2} \mathrm{O}_{2}$ system is fast, ${ }^{41)}$ and this suggested the possibility for the existence of another edaravone radical species during the earlier period.

From the findings presented here, two types of edaravone radicals were detected when edaravone was oxidized by the $\mathrm{HRP}-\mathrm{H}_{2} \mathrm{O}_{2}$ system. The first EPR signal (four-line signal, estimated hyperfine coupling constants: $a^{\mathrm{N} 1}=7.0$ Gauss, $a^{\mathrm{N} 2}=0.9$ Gauss, and $a^{\mathrm{H}}=6.7$ Gauss) was observed only under fast-flow conditions because it is unstable (Figs. 4A, 5). The second one (three-line signal, estimated hyperfine coupling constants: $a^{\mathrm{N} 1}=7.0$ Gauss and $a^{\mathrm{N} 2}=0.7$ Gauss) was observed after a lag time ( 9 min, Fig. 5), and the hyperfine coupling constant was in agreement with the value reported earlier. ${ }^{18)}$ From the results observed here, it was expected that 1) edaravone produces at least two kinds of EPR-detectable radical intermediates, 2) molecular oxygen is required (Fig. 6) during oxidization by the HRP- $\mathrm{H}_{2} \mathrm{O}_{2}$ system under aerobic conditions, and 3 ) edaravone can offer two electrons to the electrophiles (Fig. 7).

Our hypothetical mechanism of the oxidation of edaravone is presented in Chart 1. At physiological $\mathrm{pH}$, edaravone exists in an anionic form, because the $\mathrm{p} K_{\mathrm{a}}$ value is $7.0 .^{10)}$ When edaravone was oxidized by hydroxyl radicals or other electrophiles, an edaravone radical consistent with the four-line EPR signal was first produced by one-electron oxidation (radical species 1 in Chart 1 ) at a rate of $3.0 \times 10^{10} \mathrm{M}^{-1} \mathrm{~s}^{-1}$. This edaravone radical intermediate immediately interacts with molecular oxygen to form edaravone peroxyl radical ${ }^{10)}$ (Fig. 6). If the oxygen molecules were absent, 4,4-bis-(3- 


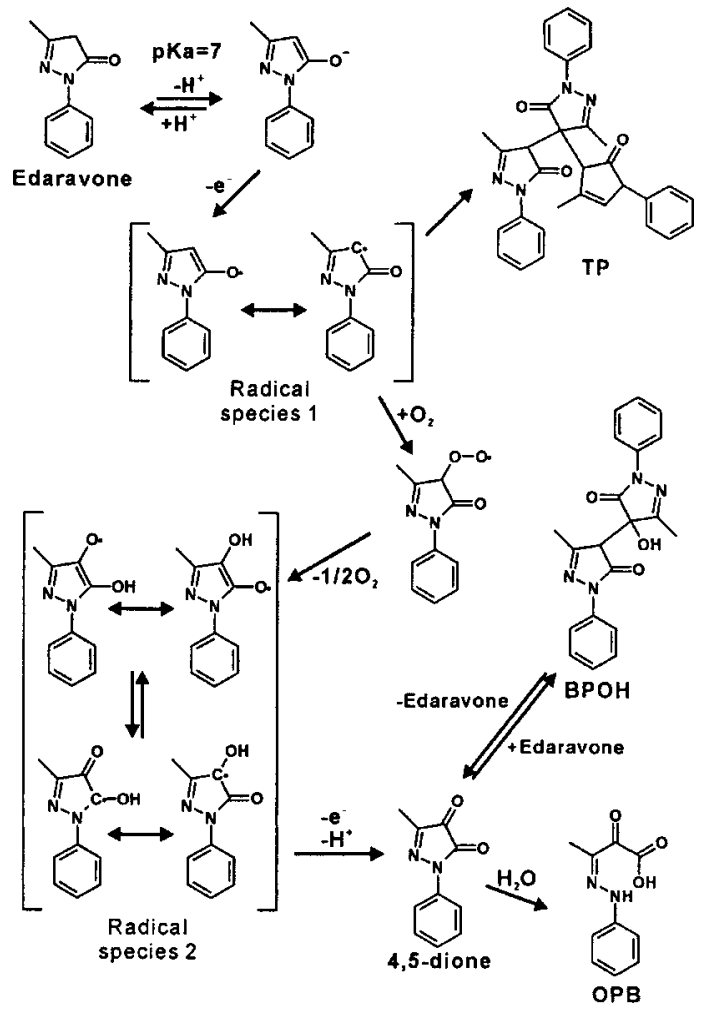

Chart 1. Hypothetical Reaction Mechanism of Edaravone Decomposition by Oxidation

methyl-1-phenyl-2-pyrazolin-5-on-4-yl)-3-methyl-1-phenyl2-pyrazolin-5-one (TP) would be produced as reported previously by the radical-radical interaction. ${ }^{20)}$ Two molecules of edaravone peroxyl radical react with each other, then produce two molecules of edaravone alkoxyl radical with elimination of one molecule of molecular oxygen ${ }^{42)}$ The hydrogen rearrangement reaction results in the progressive appearance of a second radical species ${ }^{43}$ (radical species 2, in Chart 1) (Fig. 5). 4,5-Dione could be produced by elimination of a hydrogen atom and one electron, following the generation of OPB by hydrolysis. ${ }^{10)}$ The formation of 4-hydroxy-4-(3methyl-1-phenyl-1H-pyrazolin-5-on-4-yl)-3-methyl-1phenyl-1H-pyrazolin-5-one (BPOH) is expected to be due to the interaction between 4,5-dione and edaravone. ${ }^{20)}$

These hypotheses are in consistent with the predicted reaction mechanisms using the electron density functional technique. ${ }^{11)}$ This scheme can be summarized as follows:

edaravone $+\mathrm{O}_{2}+\mathrm{H}_{2} \mathrm{O} \rightarrow \mathrm{OPB}+2 \mathrm{H}^{+}+2 \mathrm{e}^{-}$

In conclusion, it appeared that edaravone is capable of transferring two electrons to electrophiles, and interacts with hydroxyl radical at a rate of $3.0 \times 10^{10} \mathrm{M}^{-1} \mathrm{~s}^{-1}$ in aqueous solution, which is same order $\left(\cong 10^{10} \mathrm{M}^{-1} \mathrm{~s}^{-1}\right)$ as that of well known antioxidants such as ascorbic acid $\left(10^{10} \mathrm{M}^{-1} \mathrm{~s}^{-1}\right)$, vitamin $\mathrm{E}\left(10^{10} \mathrm{M}^{-1} \mathrm{~s}^{-1}\right)$ and butylated hydroxyltoluene $\left(6 \times 10^{10} \mathrm{M}^{-1} \mathrm{~s}^{-1}\right){ }^{44)}$ In addition, Yamamoto et al. reported that $50 \mathrm{~mm}$ edaravone inhibited the aerobic oxidation of phosphatidylcholine liposomal membranes, initiated both with a water-soluble initiator 2,2'-azobis(2-amidinopropane)dihydrochloride (AAPH) and with a lipid-soluble initiator 2,2'-azobis(2,4-dimethylvaleronitrile) (AMVN), as efficiently as did $100 \mathrm{~mm}$ ascorbate and $2 \mathrm{~mm}$ vitamin E, re- spectively ${ }^{10)}$ These data suggest that edaravone may work as a good antioxidant. It remains unclear that hydroxyl radical scavenging activity is totally responsible for the physiological effects of edaravone, and whether edaravone radicals 1 or radicals 2 mainly contribute to the antioxidant activity in vivo from these results. Due to the high reactivity of hydroxyl radical for organic compounds with a diffusion-controlled rate $\left(\cong 10^{10} \mathrm{M}^{-1} \mathrm{~s}^{-1}\right)$, it is likely that a sub-millimolar or greater concentration would be required to be able to compete for ${ }^{\circ} \mathrm{OH}{ }^{45)}$ Therefore, it is necessary to study the accumulation of edaravone in the injured region of the brain and to clarify the interactions between edaravone or its radical intermediates with physiological high molecular compounds for attenuation of brain damage through free radical scavenging.

\section{References}

1) Halliwell B., Gutteridge J. M., Methods Enzymol., 186, 1-85 (1990).

2) Chapple I. L., J. Clin. Periodontol., 24, 287-296 (1997).

3) von Zglinicki T., Burkle A., Kirkwood T. B., Exp. Gerontol., 36, 1049-1062 (2001).

4) Darley-Usmar V., Halliwell B., Pharm. Res., 13, 649-662 (1996).

5) Flamm E. S., Demopoulos H. B., Seligman M. L., Poser R. G., Ransohoff J., Stroke, 9, 445-447 (1978).

6) McCord J. M., N. Engl. J. Med., 312, 159-163 (1985).

7) Abe K., Yuki S., Kogure K., Stroke, 19, 480-485 (1988).

8) Nishi H., Watanabe T., Sakurai H., Yuki S., Ishibashi A., Stroke, 20, 1236-1240 (1989).

9) Watanabe T., Egawa M., J. Pharmacol. Exp. Ther., 271, 1624-1629 (1994).

10) Yamamoto Y., Kuwahara T., Watanabe K., Watanabe K., Redox Report, 2, 333-338 (1996).

11) Ono S., Okazaki K., Sakurai M., Inoue Y., J. Phys. Chem. A, 101, 3769-3775 (1997).

12) Matuszak Z., Reszka K., Chignell C. F., Free Radic. Biol. Med., 23, 367-372 (1997).

13) Neta P., Steenken S., Janzen E. G., Shetty R. V., J. Phys. Chem., 84, 532-534 (1980).

14) Mason R. P., Methods Enzymol., 105, 416- 422 (1984).

15) Duling D. R., J. Magn. Reson. B, 104, 105-110 (1994).

16) Uchiyama M., Suzuki Y., Fukuzawa K., Yakugaku Zasshi, 88, 678683 (1968).

17) Buxton G. V., Greenstock C. L., Helman W. P., Ross A. B., J. Phys. Chem. Ref. Data, 17, 513-886 (1988).

18) Lehmann F. M., Bretz N., von Bruchhausen F., Wurm G., Biochem. Pharmacol., 38, 1209-1216 (1989).

19) Zhuang Q., Scholz F., Pragst F., Electrochem. Commun., 1, 406-410 (1999).

20) Watanabe K., Watanabe K., Hayase T., Jpn. Pharmacol. Therap., 25, 1699-1707 (1997).

21) Blois M. S., Nature (London), 181, 1199-1200 (1958).

22) Barinaga M., Science, 272, 664-666 (1996).

23) Minematsu K., Fisher M., Li L., Davis M. A., Knapp A. G., Cotter R. E., McBurney R. N., Sotak C. H., Neurology, 43, 397-403 (1993).

24) Takano K., Tatlisumak T., Formato J. E., Carano R. A., Bergmann A. G., Pullan L. M., Bare T. M., Sotak C. H., Fisher M., Stroke, 28, 1255-1263 (1997).

25) Bordi F., Terron A., Reggiani A., Eur. J. Pharmacol., 378, 153-160 (1999).

26) Hickenbottom S. L., Grotta J., Semin Neurol., 18, 485-492 (1998).

27) Valentino K., Newcomb R., Gadbois T., Singh T., Bowersox S., Bitner S., Justice A., Yamashiro D., Hoffman B. B., Ciaranello R., Miljanich G., Ramachandran J., Proc. Natl. Acad. Sci. U.S.A., 90, 7894-7897 (1993).

28) Cross A. J., Jones J. A., Baldwin H. A., Green A. R., Br. J. Pharmacol., 104, 406-411 (1991).

29) Leach M. J., Swan J. H., Eisenthal D., Dopson M., Nobbs M., Stroke, 24, 1063-1067 (1993).

30) Gandolfo C., Sandercock P., Conti, M., Cochrane Database Syst. Rev., CD001924 (2002).

31) D’Orlando K. J., Sandage B. W., Jr., Neurol. Res., 17, 281-284 (1995). 
32) Halliwell B., J. Neurochem., 59, 1609-1623 (1992).

33) Kontos H. A., Circ. Res., 57, 508-516 (1985).

34) Bromont C., Marie C., Bralet J., Stroke, 20, 918 - 924 (1989).

35) Oishi R., Itoh Y., Nishibori M., Watanabe T., Nishi H., Saeki K., Stroke, 20, 1557-1564 (1989).

36) Mizuno A., Umemura K., Nakashima M., Gen. Pharmacol., 30, 575578 (1998).

37) Maskos Z., Rush J. D., Koppenol W. H., Free Radic. Biol. Med., 8, $153-162$ (1990).

38) Floyd R. A., Watson J. J., Wong P. K., J. Biochem. Biophys. Methods, 10, 221-235 (1984).

39) Floyd R. A., Henderson R., Watson J. J., Wong P. K., J. Free Radic. Biol. Med., 2, 13-18 (1986).

40) Yamamoto T., Yuki S., Watanabe T., Mitsuka M., Saito K. I., Kogure
K., Brain Res., 762, 240-242 (1997).

41) Glover R. E., Koshkin V., Dunford H. B., Mason R. P., Nitric Oxide, 3, 439-444 (1999).

42) Koenig T., "Free Radicals," Vol. 1, ed. by Kochi J. K., John Wiley \& Sons, New York, 1973, pp. 113-155.

43) Wilt J. W., "Free Radicals," Vol. 1, ed. by Kochi J. K., John Wiley \& Sons, New York, 1973, pp. 334-501.

44) Ye J., Ding M., Zhang X., Rojanasakul Y., Shi X., Ann. Clin. Lab. Sci., 30, 65-71 (2000).

45) Symons M. C. R., Gutterridge J. M. C., "Free Radicals and Iron: Chemistry, Biology, and Medicine," Oxford University Press, New York, 1998.

46) Forni L. G., Mora-Arellano V. O., Packer J. E., Willson R. L., J. Chem. Soc. Perkin Trans. II, 1988, $1579-1584$ (1988). 